\title{
Cultural Inequality and Sustainable Development
}

\author{
Most. Asikha Aktar * \\ Assistant Professor, Department of Economics \\ Cumilla University, Cumilla, Bangladesh \\ Email: asikharita@gmail.com
}

Md. Mahmudul Alam

Senior Lecturer, School of Economics, Finance \& Banking

Universiti Utara Malaysia, Sintok, Kedah, Malaysia

Email: rony000@gmail.com

*Corresponding Author

\section{Citation Reference:}

Aktar M.A., \& Alam M.M. (2021). Cultural Inequality and Sustainable Development. In: Walter Leal Filho et al. (eds), Reduced Inequalities: Encyclopedia of the UN Sustainable Development Goals. Springer, Cham. ISBN: 978-3-319-71060-0. (online) https://doi.org/10.1007/978-3-319-71060-0_5-1

This is a pre-publication copy.

The published article is copyrighted by the publisher. 


\section{Cultural Inequality and Sustainable Development}

\section{Definition}

Cultural inequality is generally intertwined with social, political and economic issues that defy inequality in income, wealth, gender, information, principles, arts, regulations, standards, values, and other abilities, as well as customs that are required to be the part of a society (Avruch 1998). With deeper sense, cultural inequalities blur the straightforward discrepancy accompanied by micro and macro causal processes by putting forward the special effects of cultural stereotypes on personalities and individual identities (Crossick and Kaszynska 2014). Accordingly, the reduction of cultural inequality has become a focal issue for sustainability researchers, and it is encouraging to explore new ways of addressing this complex issue (Doyle and Stiglitz 2014).

\section{Introduction}

Generally, Inequality refers to the unfair situation of society where some people get more opportunities and favors than others. Though the term 'inequality' is mostly distinguished as economic, social and political inequality both at local and global level (Doyle and Stiglitz 2014), 'Cultural Inequality' specifically encompasses all forms of inequality and emerges as a central issue for the post-2015 sustainable development agenda (UNESCO 2012). "Cultural inequality" emanates from discrimination, stigmatization, and labelling of certain groups of people in society, such as racial minorities, refugees and migrants, women, and LGBT (Kohn 1977). In other words, cultural inequality is the reciprocal feedback loops of the persistent inequalities amongst groups and entities (Charles 2008). Our work focuses on cultural inequality that arise from cultural processes and how its effects the Sustainable Development Goals. This section tries to give a better idea regarding what is culture and how the cultural process leads to cultural inequality.

Nowadays, two areas are attracting particular attention of the sustainability researchers: Firstly, how public policy responses, management strategies, traditional decision making approaches and education are insufficient for addressing sustainable development issues, and secondly, is the rising interest in recognizing productive pathways for addressing these deficiencies. As practitioners and researchers have struggled with the theme of cultural sustainability, a recognition of it has shown that problems like cultural inequality make it challenging to tackle conclusively.

\section{What is Culture?}

The most used and commonly acknowledged idea of culture is the British generated idea that has been bearing long history, from the period of Victorian era (O'Brien 2014; Lee 2008). Moreover, Culture as a concept was exposed precisely by the British Labour government during the time period of 1997-2010, which directly tied culture with social goods production ability. Additionally, culture could lessen the effects of societal exclusion, such as incidence of poverty, lower concentrations toward educational attainment or the effects of long-term labour market exclusions. However, as the concept culture is as old as mankind; it means different things to different people. At an initial stage, attitudes, personality traits or values are the cultural means and important factors to find the differences between economics and social success (Kohn 1977; Wilson 1987; Keister 2008). Others traits of culture explain the important 
phases of understanding, that may vary under the different categories of social groups (Anderson 1976; Willis 1977; Fenstermaker and West 2002).

Lastly, the concept culture is defined as "specific institutions of knowledge and creativity such as language, science, religion, film, and literature" (Gusfield 2006). Such meanings of culture are neither comprehensive nor exclusive.

\section{How Cultural Process Lead to Cultural Inequality?}

An interesting point of culture is that it can solve social problems. For example, it can be created again by the expansion of cultural inequality (Lamont et al. 2014). Therefore, there exist two kinds of illustration behind the association between culture and inequality (O'Brien and Oakley 2015). On the one hand, culture is defined by raising questions like what is, and what is not, of value or worth. The definition of culture in this way is called a contested definition which is directly connected to hierarchies. This perspective helps to understand the relationship between cultural hierarchy (i.e. some cultural systems obtain more value compared to others) and social hierarchy (i.e. ethnicity, class, gender etc.).

On the other hand, the authors stated that culture is defined in terms of culture for the government. Accordingly, the concept of 'Culture' as is for different economics and social purposes suggests that "culture can also be used for performing various governmental activities". Thus, the significance of culture for government is justified by determining the effectiveness and efficiency of culture to preserve social and economic well-being. The use of culture in this way suggests that the importance of culture is recognized by the state in relations to social issues. The authors stated also that, "even though the state expects that culture can provide equitable distributions and allocations of outcomes, but in reality, culture for government is associated with inequality" (O'Brien and Oakley 2015).

Moreover, for understanding the present situation of global society, the role of inequality is of vital importance (Wilkinson and Pickett 2009; Dorling 2015). There exists volume of literature on inequality with traditional factors, such as income and gender (CSI 2015a and 2015b), but the literature on inequality from a cultural perspetive is very little (Lamont et al. 2014). Therefore, it has been suggested that complete action should be taken for associating inequality with cultural roles. More precisely, cultural inequality which is related to different dimensions, such as sex, age, disability, religion, ethnicity, economic and sexual orientation, is produced or reproduced by the two sorts of cultural processes (Lamont et al. 2014):

1. Identification (racialization and stigmatization)

2. Rationalization (Standardization and evaluation)

\section{Identification}

Identification is the first type of cultural processes which assumes that people from a large society can identify themselves or can be identified by others based on a wide range of individualistic characteristics, including age, sex, race, gender, nationality, citizenship, ethnicity, religion, language, education, etc. (Owens et al. 2010). Therefore, for studying cultural processes, Jenkins (2008) postulates that, "we focus on identification by tracing specific classification of people into groups and categories, which is central to both racialization and stigmatization.

In Sociology, racialization is defined as, "the process of ascribing ethnic or racial identities to a relationship, social practice or group that did not identify itself" and, as such, describing inequality racialization implications can be ambiguous and open ended (Lamont et al. 2014). Many researchers who focused on racialization face allegations from the social communities 
and political representatives (Polletta 2009). To make the racial classification system stable, the subordinated group has a vital contribution because they create such a group which is more focused on their ethnic-racial identity. Goffman (1963) in his classic book "Stigma: Notes on the Management of Spoiled Identity", refers to "an attribute that is deeply discrediting". Link and Phelan (2001) comprehended it as by introducing the characteristics of classification, negative labelling, separation and status discrimination. Presently, social scientists are more focused on stigmatization rather than stigma, and they defined stigmatization as, "the process of designating symbolically and qualifying negatively, identities and differences" (Dubet et al. 2013; Fleming et al. 2012).

\section{Rationalization}

Rationalization is a sociological concept and closely related to the work of famous sociologist Weber (1978) who described rationalization as means of transformation toward modern era and it is coupled with the emergence of capitalism, the birth of the nation-state and the development of modern science(Lamont et al. 2014). To put it another way, rationalization leads to foster movement towards modernization by replacing traditional values and norms. On the contrary, such movement also boosts inequality which is generally reproduced and legitimized as an effect (Foucault 1977; Latour 1993). More so, Weber's analysis on bureaucracy deals with two sub-processes of rationalization, namely standardization and evaluation, that are closely related to bureaucratic organizations in modern society, where cultural processes unfold and may surely result in inequality (Lamont et al. 2014).

Furthermore, Standardization, the process by which individual, groups and institutions create 'uniformities across time and space' through 'the generation of agreed-upon rules (Timmermans and Epstein 2010). Therefore, inequality can be increased or decreased through the process of standardization because it has the power to intensify or lessen the consequences of inequality, and it indicates that the standardization results of inequality are not deliberate, direct, but they are open-ended (Buchmann et al. 2010). Although in the modern society standardization is called the main feature of daily societal life, few researchers have found its meaningful analytical perception of describing in what way inequality develops and persists in the society at the macro-level. As for example, Neckerman's analysis on the use of standard in the education system has been documented here to illustrate the relations amongst standardization-social inequalities more clearly. In 2007, Neckerman's study has analysed the consequence of introducing standardized and IQ testing system at the education policy of America and Chicago local area in the 1920s. Her analysis shows that how standardized and IQ testing scores are used to select a candidate who is suitable for taking admission at the top vocational schools in America and Chicago. As a result, such reform of education policy has deprived African-American people by restricting access to the best schooling who are at the lower levels of the socio-economic class.

On the other hand, evaluation is another sub-process of rationalization that deals with the three most common values of social life. According to Beckert and Musselin (2013), these are negotiation, definition, and stabilization. Lamont (2012) argues that evaluation also depends on several sub-processes. One of the most important sub-processes of evaluation is categorization ('which group of entity is belong under consideration'), and another is legitimation ('either recognized by own value or by others value of an entity'). Lamont also has defined evaluation as "a process of reproducing inequality that results in winners and losers". For instance, the daily performances in workplaces, school and social institutions can evaluate the cultural process through the rankings, or the disparity allocation of desirable resources. As for an example, in the labour market, for selecting people (i.e., competent and 
decent) from a large pool of applicants, the evaluation procedure is used at a greater extent. Moreover, there are three broad dimensions of cultural inequality, which are produced or reproduced by cultural processes (Lukes 1974) that are given below.

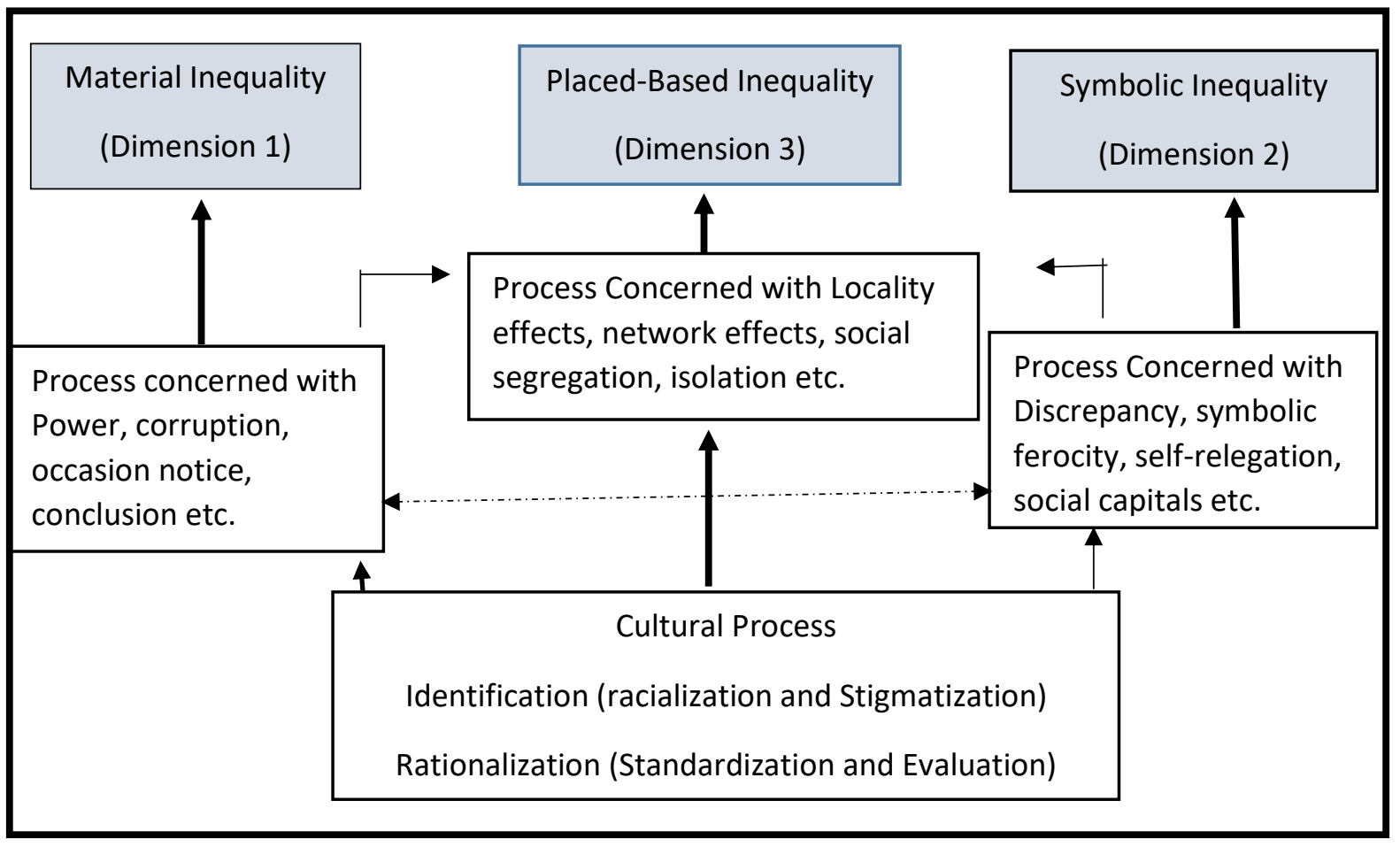

Figure 1: Cultural Process to cultural Inequality (Adapted from Lemont et.al. 2014)

\section{SDGs and Cultural Inequality}

The aim of this section is to discuss how cultural inequality impacts on sustainable development goals. The explanation of such issue entails the relationship between culture and sustainable development goals, by taking into account the culture as an overreaching dimension of sustainable development, and the contribution of culture to sustainable development as well as hindrances in achieving sustainability.

\section{Culture as an Overreaching Dimension of Sustainable Development}

Both the term 'culture' and 'sustainable development' are broad concepts, cover several aspects of life and comprise past to future. According to Raymond Williams (1976), Culture as a concept is one of the most multiple words in English as a Language, and is difficult to define. Williams termed culture from three distinct aspects that gained popularity both in research as well as in policy: culture as a universal way of developing psychic, artistic and intellectual thinking, culture as a specific approach to life, and culture as a process of overall works and activity. Like culture, the term sustainable development is also problematic in defining, and also there is always more than one definition of sustainable development and its scope (Du Plessis 2009; Morelli 2011; Redclift 1989; Vos 2007). However, in 1987 the Brundtland report provided the most popularly employed definition, which is, "sustainable development is the development that meets the needs of the present without compromising the ability of future generations to meet their own needs". In addition, the most frequently used definition of 
sustainable development is provided by Caring: "improving the quality of human life while living within the carrying capacity of supporting ecosystems" (Munro 1995).

However, traditionally Sustainable Development is defined as a three-dimensional concept, which encompasses the interactions among economic, social, and environmental aspects. Scammon (2012) argued that culture is an important dimension as social, environmental and economic dimensions of sustainability which is expected to influence the triple bottom line: environment, society, and economy simultaneously in a holistic approach. As such, culture is related to the economy by way of income generation activities and employment opportunities (UNESCO 2012). Furthermore, culture welcomes people from different backgrounds by exhibiting its artworks, or by opening historical buildings and tourists areas. In this way, culture makes monetary income which is generated from the visitors (Adamson et.al 2012). Therefore, the interaction between an economy and culture implies preservation and protecting of all the tangible and intangible elements of culture, like oral histories, art and traditions, social values, customs, festivals, knowledge, natural and universal practices, art and skills for traditional craft of culture in a way that fosters economic development (UNESCO 2012).

In addition, there exists a close interaction between culture and society (Scammon 2012). Social issues, for example, issues related to poverty, education, health, civic management etc. traditionally have been incorporated into cultural sustainability in the sense that distributes scarce resources among societies in such a way so that everyone in the society can enjoy a better standard of living. Similarly cultural issues, for example, issues related to art, diet, and music, tangible and intangible cultural capital etc. by tradition are incorporated into the social sustainability in the sense that takes account of society's ability to ensure facilities which are essential for maintaining better life for its members. Thus, "culture shapes the society that in turn shapes the culture" first expressed by Winston Churchill (Brocchi 2008).

Finally, the interaction between culture and environment implies that culture contributes to the environment by providing cultural capital that helps to increase awareness and responsibility regarding environmental quality (Throsby 2003; Wessels 2013). However, the interactions also imply that cultural sustainability means producing and preserving cultural resources i.e. structure of buildings, like the mills that hold a community's culture with environmentally friendly materials, taking into account the concerns for environmental degradation (Maniates 2010).

Therefore the overall issue implies that to meet the goal of sustainability, consider culture as a starting point which encloses all the (i.e. environment, social and economic) pillars of sustainability. As an illustration- The Human Development Report (2003), prepared by the United Nations Development Programme, explain such connections:

"The livelihood of the people depends on environmental services. Efficient environmental practice can create income-generating opportunities which lead to increase the wealth of the people, and they know better about the use of their rights which motivate them to take part in decision making on a political level"( Human Development Report, 2003).

This storyline implies that the environment affects the economy through income-generating opportunities whereas the economy affects the social dimension by increasing participation in decision-making. Thus, environment, economic and social factors simultaneously affect the culture that is the way of life (livelihood). Thus, culture is capable of being integrated within sustainable development as the central pillar. Such critiques arguing that culture should be 
considered not only as an additional pillar of sustainable development along with economic, environmental, and social pillar rather considered as a strong key element of sustainable development framework (Nurse 2006). Therefore after thirty years of Brundtland report, culture as a pillar of sustainable development first emerged at the international meeting in Mauritius. The meeting was held for Small Island Developing States (SIDS), and that is known as 'Barbados +10 '. The main aim of this meeting was to evaluate the policy of action for SIDS in the context of sustainability. A number of new and the emerging issues were outlined in the meeting, where culture was recognized as a fourth pillar of sustainable development and considered as an overarching dimension of sustainability (Nurse 2006).

\section{Cultural Contributions to Sustainable Development}

As an overall dimension of sustainability, the significance of culture is obvious (Dessein et. al. 2015). According to Scammon (2012), Cultural sustainability provides the way to enhance sustainability in the environment, economy, and society, and this correspondently promotes the cultural values and its identity by different ways, like traditions, collaboration, art and craft, social interaction, transfer of knowledge, customs, and policies. On the other hand, the post2015 agenda recommends that on the basis of correlation in economic, social and environmental dimensions, culture as the driver and enabler can motivate the sustainable development on the wide range (UNESCO 2012).

At this instant, indicators, statistics, and data on the cultural sector and cultural motions have underscored that as a driver, culture has a good impact on sustainable development (UNESCO 2012). At present global economy, cultural \& creative industries are being considered as one of the fastest sectors with growth rates of $17.6 \%$ for Middle East, $13.9 \%$ for Africa, $11.9 \%$ for South America, 9.7\% for Asia, 6.9\% for Oceania, and 4.3\% for North and Central America respectively ( $\mathrm{PwC}, 2008)$. More importantly, to develop a rich cultural tradition and sustainable labour force, industry, tourism and infrastructure are the special tools which serve as revenue for a country. As an enabler, culture has gained transformative power by means of widening current development approaches and making the development much more relevant to the necessities of societies (UNESCO 2012). Therefore, sustainable, inclusive and equitable outcomes would be possible if the development interventions are very much responsive to the cultural context.

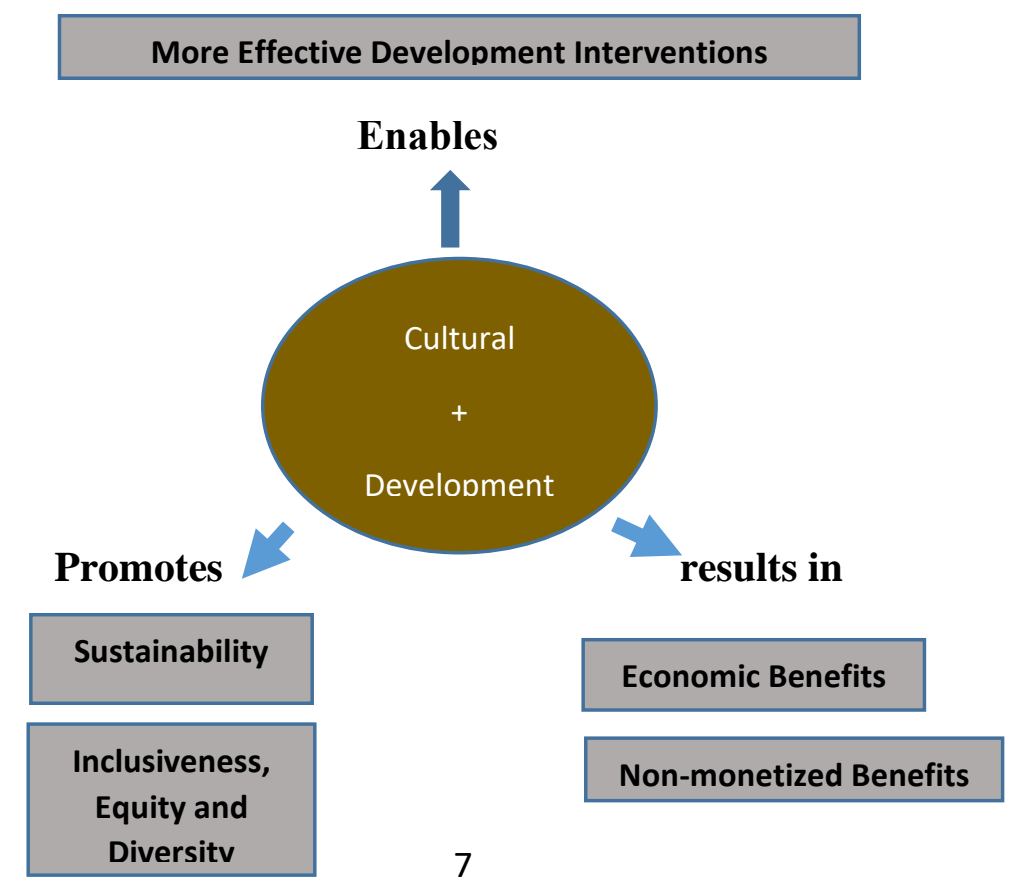


Figure 2: How Culture Contributes to Sustainable Development (adapted from UNESCO, 2012)

To be precise, in the light of contribution of culture to sustainable development, Soini and Birkeland (2014) using the concept of 'cultural sustainability' have reviewed and analyzed numerous scientific peer-reviewed articles and found out seven principal "storylines" that shaped the connotations of cultural sustainability. Culture has been stated as a fourth dimension of sustainability by some of the storylines. While others perceived the contribution of culture as a way of attaining all three goals of sustainability (i.e., economic, environmental and social) or starting point for moving toward a more sustainable society (Soini and Birkeland 2014). Although perceptions of all the storylines were coinciding, three main contributions of culture to sustainable development are revealed. These are redefined here as "representations" (Connelly 2007) [See Figure 3 depicted each contribution of culture to sustainable development]

The first representation considers culture as the fourth pillar of sustainability, and implies that culture can play an independent role in sustainable development like the other three pillars. More precisely, the first representation stands for culture in sustainability. The second representation implies that culture can play an intermediating role of achieving social, economic and ecological sustainability. More precisely, the second representation represents culture for sustainability, and it suggests that for achieving economic development at the local or regional level, the importance of culture is unavoidable. In addition, for attaining long term economic development, the values and perceptions of culture must be taken into consideration. The third representation stands for culture as sustainability, and it considers culture as a predominant pillar for meeting the overall aims of sustainable development as it encompasses all the other three pillars of sustainability.
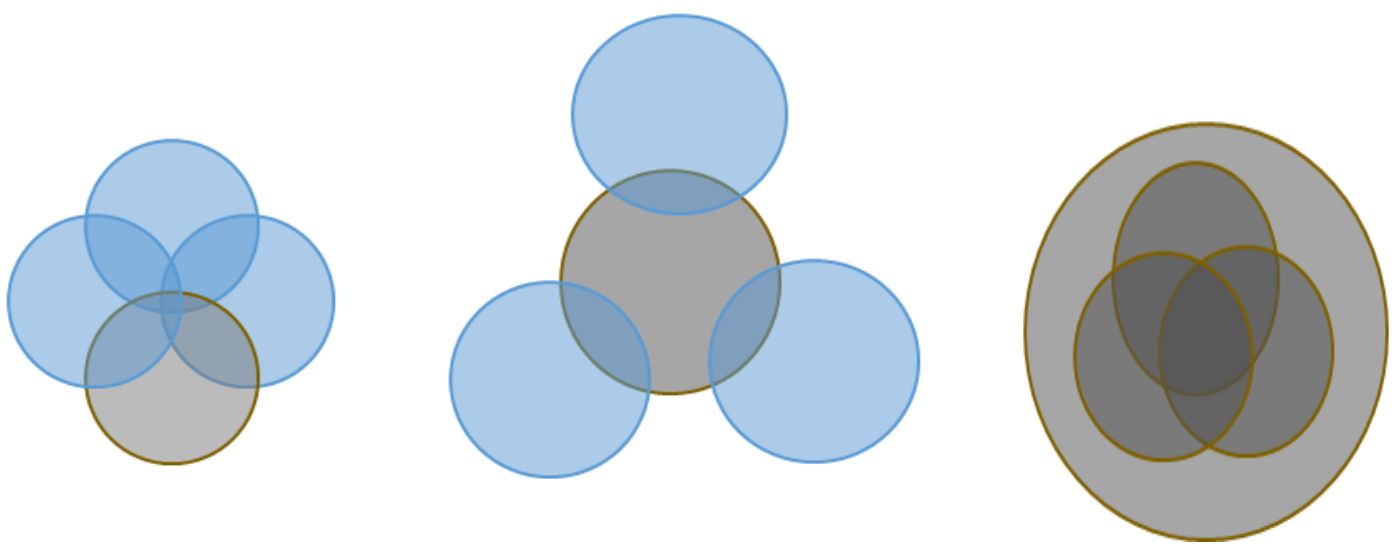

Figure 3: Three Contributions of Culture to Sustainable Development (Adapted from Dessein et.al. 2015)

The above displayed diagram represents the relationship between culture and sustainable Development from different approaches. In the figure, the cultural dimension of sustainability has been symbolized by the dark grey colour whereas light blue colour highlights ecological, economic and social dimensions of sustainability. The first diagram explains culture as the 
fourth pillar of sustainability; on the other hand, culture has been explained as a mediator of all three pillars of sustainability in the central diagram, and in the final diagram, it has been explained as a foundation of transition towards sustainable development. Moreover, these three representations play an important role to explore the relations between culture and sustainability in a more sophisticated way. For example, to explain precisely, the relations between all of the three representations are analysed systematically and cooperatively by the way of eight dimensions (Soini and Dessein 2016). These dimensions reproduce representations in the way of readdressing the crucial variable "culture" \& "sustainability". Such as-

Dimension- 1(definition of culture): The first representation defines culture by means of capital and the most common system of religious, intellectual or aesthetic development. On the other hand, take into account of the Williams's second definition of culture, the second representation defines culture as a way of life (Williams 1985; Soini and Dessein 2016). That means all aspects of life are regulated and influenced by culture. Likewise, the significance of environment is also enlightened by culture. However, in the third representation, culture is seen as a symbiosis.

Dimension-2(culture and development): The first representation defines culture as an achievement of development. On the contrary, the second representation defines it as a way of means and condition for achieving development. Finally, the third representation refers development as such that it is considered to be a cultural process.

Dimension-3(value of culture): The first representation defines the culture that has certain intrinsic values (also called inherent) whereas, in the second representation, culture has both intrinsic and instrumental values, and in the third representation, cultural value is embedded.

Dimension-4 (culture and society): The role of culture for society is complementing, and it implies that in order to maintain the sustainable society, putting emphasis on cultural aspects is needed. The second representation expresses the idea that the role of culture for running sustainable society is affording and progressing (Gibson, 1977), and in the third representation, the role is transforming, and that indicates culture as a change factor which helps society to be transformed to a more sustainable society.

Dimension-5(Culture and nature): Culture is considered as the most common way of knowing nature by the first representation. On the other hand, in the second representation, the interaction between culture and nature is seen, and it implies that they act together for processing daily life activities and nature which is a significant contributor to the end result of all individual activities. Moreover, in the third representation, as an indicator of culture, the importance of nature is recognized along with the economy and society. This is also reformed by different useful meanings and symbols (Soini and Dessein 2016).

Dimension-6 (Policy Sectors): In the first representation, it is clearly stated that cultural activities are directly linked to government activities; for example, this involves cultural diaspora and work and experience related to that which also promotes the feelings and emotions of the people. In the second representation, policy related to every sphere of social life that is nurtured by culture is covered. In addition, the third representation requests for designing an effective policies that naturally tackle all the barriers in the path of transition towards sustainable development. 
Dimension-7(Modes of Governance): In the context of Kooiman's (2003) work, although the first representation is mainly concerned with hierarchical governance system, it also includes other forms of governance system and interested party related to investors, other policy sectors, and citizens. Thus, in the second representation, an ideal governance structure is designed in such a fashion that fires up the role of culture for attaining sustainable development that is known as a second order governing. Then, the third representation calls for new modes of governance which are considered as self-governance that must be new one, suggesting settingup the mode of meta-governance.

Dimension-8(Research Approach): The first representation indicates that for evaluating culture as an independent pillar of sustainability, it is appropriate to conduct either mono or multidisciplinary research approach. On the contrary, the second representation indicates that interdisciplinary research approach is appropriate that combines all the approaches and methodologies carried out by all the dimensions of sustainability. Finally, the third representations suggests that trans-disciplinary research approach is appropriate, and that offers a concrete framework for understanding societal transformation (Soini and Dessein, 2016).

Thus, each dimension presented here has addressed culture by different approaches in the perspective of sustainable development. Therefore, it is important to be aware of the use of the term culture in the perspective of sustainable development, and the way culture is addressed. However, the other key thing is that when culture relates sustainable development, the term culture is not same for all, and the different 'cultures' create inequality of cultures because political and historical situations affect them (Doyle and Stiglitz 2014). Thus culture can also hinder sustainable development by generating uneven development and emulation effect. Currently inequality among cultures induced by globalization emerged as one of the new emerging concerns for achieving the sustainable development goals.

\section{Impacts of Cultural Inequality to Sustainable Development Goals}

The Sustainable Development Goals (SDGs), approved by the UN General Assembly in 2015, comprise seventeen goals and one-hundred sixty-nine targets. It is suggested that the wide acceptance of the ideal of sustainable development is related to the recognition of the principles of sustainable development, which remains largely the same across all disciplines and refers to "reduced inequalities among and within nations". These principles include five interconnected equity principles that are deduced from the Stockholm Declaration and the Rio Instruments and categorized by Haughton (1999) given the following:

a) Inter-generational equity (Futurity)

b) Intra-generational equity (social justice)

c) Terrestrial equity (responsibility related to territories)

d) Technical equity (basic needs of people) and

e) Inter-species equity (the importance of biodiversity)

These five equity principles, though appearing distinctly, collectively form the basis of the notion of sustainable development, and it is suggested that the integration of the principles would be beneficial to achieving the aim of sustainable development. Above all, it is not possible to achieve the sustainable development goals if any part of the world population is excluded from the opportunities of enjoying a better life. According to Talmaciu (2015), sustainable development can be boosted only when the population of a country is treated 
equally, directed by a strong ethical work environment and can get the equal opportunities to learn from others. All of those are intimately connected with the country's cultural matrix.

But currently, inequality persists continuously at a larger extent throughout the world as reported by UN-agencies and the World Bank. It threatens SDGs through restraining poverty reduction, socio-economic development, environmental quality and positive self-images (Andrews et al. 2014). The growth of inequalities suggests policymakers should attain to the SDGs framework, and the first and foremost action is to identify factors causing inequality. In this context, Talmaciu (2015) emphasized that cultural aspects of different nations can determine their economic environment, Freytag and Turik (2007), and the cultural variables play significant role to increase inequalities in the distribution of income (Malul et al. 2010). In addition, Talmaciu (2015), also indicated that, cultural aspects obstruct sustainable development by way of unequal development.

Although reducing inequality is one of the most important goals of sustainable development, full equality is not the goal (Doyle and Stiglitz 2014). As such, there are some certain forms of inequalities that are more conducive to development. While, at a point, inequalities turn into harmful effects argued by a number of economists (OECD 2015). One of the mechanisms through which this happens is by preventing the poor people from participating in educational activities and making the rich more richer by boosting them to grip a bigger percentage of the economic share rather than making it available at all.

However, in terms of the need to be concerned about the degree of inequality, inequality that is too wide, is harmful to the society. Furthermore, once cultural inequality arises, harmful social, economic, and environmental effects become evident. Since culture is considered as an umbrella of social, economic and environmental dimensions (O'Brien and Oakley 2015), sustainable development in terms of cultural inequality includes the following:

Economic Inequality- is considered as destructive factor of obtaining sustainability. It leads to reduce development by the uneven layout of income as well as by reducing aggregate demand associated with willingness to spend by the rich and poor within and between nations.

Social inequality- One of the most recognizable forms of inequality, and it has been pointed out by Alan Krueger who was the ex-Chairman of Economic Advisors in the United States Council, is known as inequality of opportunity. According to Alan Krueger (2013), inequality of opportunity means lack of opportunity of enjoying socioeconomic mobility equally. For example, people who are born at the lower portion of the economic pyramid almost remain there until the end of their life. The fact is that they are always convicted to their stereotypes. Thus, inequality restricts the opportunity for people who carry the burden of lower- class status and also disregard their potential contribution to socio- economic development which leads to slower long-term economic growth.

Environmental inequality- is the inequality in control of resources among generation which leads to loss of environmental sustainability. However, environmental inequality can be influenced by the household, community, national, and international channel (DESA 2015); for example, the rich consume more compared to the poor household, so the contribution of the rich household to pollute the environment is greater. Utilization of shared efforts approach plays an important role in protecting environmental resources, but such an approach is 
restricted by the influence of community channel, where a group of individual who pay less efforts than their fair allocation of the efforts. National channel influences the environment via policy formulation regarding "income inequality". Even though the social group of rich people contains a small number of total population, they exert significant power to formulate national policy in order to meet their self -interest parallel to the policies that are not acceptable for the protection of the environment. The international channel also influences the environment in a similar way of national channel.

Moreover, cultural inequality includes economic, social and environmental inequality simultaneously, and this is a widespread concern for sustainable development. It is claimed that the concept of culture needed to achieve the sustainability transition is already in place, however, there is a gap between approach and actions, both at the individual and collective level that need to be bridged. Haque (1999) claims that sustainable development is "threatened by the widespread cultural inequality". Therefore, to protect, promote and maintain sustainable development that will benefit present and future generations, it is essential to reduce cultural inequality by eliminating the gap between approach and actions.

\section{Beyond Cultural Inequality that Hinders SDGs}

Culture is the interactive of common characteristics that influence a groups' response (Hofstede 1980), which is considered as a more powerful dimension of sustainable development because of its power to combine all the dimensions of sustainability simultaneously (Dessein et.al 2015). Considering this point, widespread and comprehensive attention should be paid by every nation for reducing cultural inequalities throughout the world.

It is well documented that cultural inequality is growing. According to Bina Agarwal (2018), it is called one of the deepest forms of persisting inequalities today especially as it intersects with other forms of inequality such as social, economic and political inequality. And it adversely affects a country's economic, social and political well-being. Bina Agarwal (2018) also pointed that, since it is a global problem, to handle it globally is needed. This requires to explore dimensions and seek sound policies that empower the lower strata of the society without any discrimination of sex, race, and ethnicity. This involves looking for solutions or mechanisms that can 'unlock' humanity from the unsustainable trajectories that constrain innovation and limit the options available for societal transformation (Levin et al. 2012).

Over the past decades, interest and support have grown for the idea that there are intractable cultural problems that could not be resolved, using traditional methods, and instead, the problems must be addressed through political argumentation, network, and communicative approaches.

Based on the above, this paper suggests the following measures for fostering the contribution of culture to sustainable development:

1. To integrate culture into the conception, measurement, and practice of development by considering equity principles.

2. To formulate and implement cultural policies in terms of equal opportunities for all.

3. To strengthen partnerships within and between nations in order to reduce cultural imbalance.

4. To promote respect to all culture for reducing cultural inequality 


\section{Conclusions}

The theory of sustainable development is built on equity principles, suggesting equitable distribution and allocation of income, resources, and wealth for each generations. According to this theory, inequality is the pernicious issue in the path of sustainable development, especially cultural inequality that dominates all other inequalities (Borghesi and Vercelli 2002). However, the central point is that, it is impossible to achieve the goals of sustainable development if cultural imbalance that exacerbate inequality is ignored. Based on this, it has been determined by the post-MDG agenda that cultural inequality is a key barrier of attaining sustainable development, and one of the central points of the agenda is to put more focus on reducing cultural inequality between and within nations that is crucial for achieving Sustainable Development.

\section{Synonyms}

Intertwined, Defy, interactive

\section{Cross -References}

Sound-policies (Bina Agarwal)

\section{References}

Alan B. Krueger (2013) "Land of Hope and Dreams: Rock and Roll, Economics, and Rebuilding the Middle Class" (remarks, Rock and Roll Hall of Fame and Museum, Cleveland),www.whitehouse.gov/blog/2013/06/12/rock-and-roll-economics-andrebuilding-middle-class\#fulltext.

Anderson E (1976) Streetwise: Race, class, and change in an urban community. University of Chicago Press.

Andrews N, Bawa S (2014) A post-development hoax?(Re)-examining the past, present and future of development studies. Third World Quarterly 35(6), 922-938.

Avruch, K (1998) Culture and Conflict Resolution. Washington DC: United States Institute of Peace Press.

Beckert J and Musselin C (2013) Constructing Quality: The Classification of Goods in Markets. Oxford University Press.

Borghesi S and Vercelli A (2002) ANALYSIS Sustainable Globalization. Ecological Economics 44 (2003) 77_/89.

Brocchi D (2010) The cultural dimension of sustainability. Religion and Dangerous Environmental Change: Transdisciplinary Perspectives on the Ethics of Climate and Sustainability 145 .

Buchmann C, Condron DJ, Roscigno VJ (2010) 'Shadow Education, American Style: Test Preparation, the SAT and College Enrollment'. Social Forces 89, 435-461.

Charles M (2008) Culture and Inequality: Identity, Ideology, and Difference in "Postascriptive Society". The Annals of the American Academy of Political and Social Science. 619(1):41-58.

Connelly S (2007) Mapping sustainable development as a contested concept. Local Environ. $12,259-27$. 
Crossick G and Kaszynska P (2014) Understanding the value of arts \& culture The AHRC Cultural Value Project. Arts and Humanities Research council.

CSI (2015a) is the UK becoming more gender equal? Available at http://csi.nuff.ox.ac.uk/wpcontent/uploads/2015/03/CSI_9_Gender_Inequalities.pdf.

CSI (2015b) is class inequality at KS4 decreasing? Available at http://csi.nuff.ox.ac.uk/wpcontent/uploads/2015/03/CSI_11_Class_Inequalities.pdf.

Dessein J, Soini K, Fairclough G, Horlings L, Battaglini E, Birkeland, I, ... Mihailova M (2015). Culture in, for and as sustainable development: Conclusions from the COST Action IS1007 Investigating Cultural Sustainability. University of Jyväskylä.

Dorling D (2015) Injustice (revised edition): Why social inequality still persists. Policy Press.

Doyle MW, Stiglitz JE (2014) Eliminating extreme inequality: A sustainable development goal, 2015-2030. Ethics \& International Affairs 28(1), 5-13.

Du Plessis C (2009) urban sustainability science as a new paradigm for planning. In Smart Building in a Changing Climate (van den Dobbelsteen, A., van Dorst, M., van Timmeren, A., Eds.). Techne Press : 31-46.

Dubet F, Macé E, Cousin O, Rui S (2013). Pourquoi moi?. L'expérience des discriminations: L'expérience des discriminations. Le Seuil.

Fenstermaker S \& West C (2002). Doing gender, doing difference: Inequality, power, and institutional change. Routledge.

Fleming C, Lamont M, Welburn C (2012) 'African Americans Respond to Stigmatization: The Meanings and Salience of Confronting, Deflecting Conflict, Educating the Ignorant and Managing the Self'. Ethnic and Racial Studies 35, 400-417.

Foucault, M. (1977) Discipline and Punish: The Birth of the Prison, New York, NY, Random House.

Freytag A, Thurik R (2007) Entrepreneurship and its determinants in a cross-country setting. Journal of Evolutionary Economics Vol. 17, Issue 2, pp 117-131.

Gibson JJ (1977) the theory of affordances. In Perceiving, Acting, and Knowing: Toward an Ecological Psychology; Shaw, R., Bransford, J., Eds.; Lawrence Erlbaum Associates: New Jersey, NJ, USA, ; pp. 127-143.

Goffman E (1963) Stigma. Notes on the Management of Spoiled Identity. New York: Simon and Shuster.

Gusfield JR (2006) Culture. Contexts 5:43-44.

Haque MS (1999) The fate of sustainable development under neo-liberal regimes in developing countries. International Political Science Review 20(2), 197-218.

Haughton (1999) JPER 235-238.

Hofstede GH (1980) Culture's Consequences: International differences in work-related values, Beverly Hills, CA: Sage.

Jenkins R (2008) Social Identity, New York, NY, Routledge.

Keister LA (2008) Conservative Protestants and wealth: How religion perpetuates asset poverty. American Journal of Sociology 113:1237-71.

Kohn M (1977) Class and conformity: A study in values. University of Chicago Press.

Kooiman J (2003) Governing As Governance.

Lamont M (2012) 'Toward a Comparative Sociology of Valuation and Evaluation'. Annual

Lamont M, Beljean S, Clair M (2014) what is missing? Cultural processes and causal pathways to inequality. Socio-Economic Review 12(3), 573-608.

Latour B (1993) The Pasteurization of France, Cambridge, MA, Harvard University Press. 
Lee HK (2008). Uses of civilizing claims: Three moments in British theatre history. Poetics 36(4), 287-300.

Levin K, Cashore B, Bernstein S, Auld G (2012) Overcoming the tragedy of super wicked problems; constraining our future selves to ameliorate climate change. Policy Sciences 45, pp. 123-152.

Link BG and Phelan J C (2001) 'Conceptualizing Stigma'. Annual Review of Sociology 27,363-385.

Lukes S (1974) Power: A Radical View. New York, NY, Blackwell.

Malul M Bar-El R (2009) The gap between free market and social optimum in the location decision of economic activity. Urban Studies Vol. 46, No. 10, pp. 2045-2059.

Maniates M (2010) Editing out unsustainable behavior. State of the World 119-126.

Morelli J (2011) Environmental sustainability: a definition for environmental professionals. [on-line] Journal of Environmental Sustainability 1(1). DOI: 10.14448/jes.01.0002. Available at: http://scholarworks.rit.edu/jes/vol1/iss1/2.

Munro D (1995) "Sustainability: Rhetoric or Reality?" In A Sustainable World, edited by Thaddeus C. Trzyna, with the assistance of Julia K. Osborn. California: International Center for the Environment and Public Policy.

Neckerman KM (2007) Schools Betrayed: Roots of Failure in Inner-City Education, Chicago,IL. University of Chicago Press.

Nurse K (2006) Culture as the fourth pillar of sustainable development. Small states: economic review and basic statistics.11:28-40.

O’Brien (2014) Cultural Policy London: Routledge.

O'Brien D and Oakley K (2015) Cultural value and inequality: A critical literature review. Arts and humanities research council.

OECD (2015) How does income inequality affect our lives? Insights - INCOME INEQUALITY (C) OECD 2015.

Owens TJ, Robinson DT, Smith-Lovin L (2010) 'Three Faces of Identity'. Annual Review of Sociology 36, 477-499.

Polletta F (2009) it was like a fever: Storytelling in protest and politics. University of Chicago Press.

PricewaterhouseCoopers (PwC) (2008).

Redclift M (1989) Sustainable Development: Exploring the Contradictions. Routledge.

Review of Sociology 38, 201-221.

Rio +20 and Culture (2015) Advocating Culture as a Pillar of Sustainability. Available online:http://www.agenda21culture.net/index.php/docman/meetings/467rio20engdef/fil e.

Scammon, D (2012) Sustainability and Culture: How do they work together?. LCC 480 senior seminars.

Soini K, Birkeland I (2014) Exploring the scientific discourse of cultural sustainability. Geoforum 51, 213-223.

Soini K, Dessein J (2016) Culture-sustainability relation: Towards a conceptual framework. Sustainability 8(2), 167

Talmaciu M (2015) The influence of cultural variables on sustainable development: an analysis in the European context. Regional development and integration: New challenges for the EU, 22-23.

Throsby D (2003). A Handbook of Cultural Economics. Ed. Ruth Towse. 
Timmermans S, Epstein S (2010) 'AWorld of Standards but Not a Standard World: Toward a Sociology of Standards and Standardization'. Annual Review of Sociology 36, 69-89.

UNESCO (2012) UN System Task Team on the Post-2015 UN Development Agenda. Culture: a driver and an enabler of sustainable development. Thematic Think Piece.

United Nations Development Programme, UNDP (2003) Human Development Report 2003 "Public Policies to Ensure Environmental Sustainability.". New York: Oxford University Press.

Vos RO (2007) Defining sustainability: a conceptual orientation. Journal of Chemical Technology and Biotechnology 82(4), pp. 334-339.

Weber M (1978) Economy and society: An outline of interpretive sociology. Vol. 1. Univ. of California Press.

Wessels T (2013). The myth of progress: Toward a sustainable future. UPNE.

Wilkinson R and Pickett K (2009) the spirit level: Why greater equality makes societies stronger. Bloomsbury Press.

Williams R (1976) (reprinted in 2011) Keywords. A Vocabulary of Culture and Society. Routledge.

Williams R (1985). A vocabulary of culture and society. New York: Oxford.

Willis Paul (1977) Learning to labor: How working class kids get working class jobs. New York: Columbia University Press.

Wilson WJ (2012) The truly disadvantaged: The inner city, the underclass, and public policy. University of Chicago Press. 